\title{
Editorial-LED 2017
}

\section{Rainer Grün \& Frank Preusser}

This special Quaternary Geochronology volume of the Proceedings of the 15th International Conference on Luminescence and Electron Spin Resonance Dating is dedicated to the memory of Martin Aitken, one of the great pioneers in luminescence dating, who passed away on 13 June 2017, aged 95. We are pleased that Ann Wintle, herself the great Dame of luminescence dating, wrote a fitting tribute to Martin, which follows this editorial.

The 15th International Conference on Luminescence and Electron Spin Resonance Dating (LED, 2017) was held in Cape Town, South Africa, from the 7th to the 11th of July 2017. The conference was organised by Prof. Makaiko Chitambo, Rhodes University, Grahamstown, with the assistance from the National Organising Committee and International Scientific Advisory Committee. LED2017 was attended by 196 delegates from more than 30 countries. The Cape Sun Hotel provided the perfect venue for the conference, as it had a firstclass lecture hall for the oral presentations and generous rooms for the poster presentations. The limited size of the conference and the many cafes, restaurants and pubs in Cape Town gave all attendees plenty of opportunity for debates, discussions, setting up new research collaborations, chats and gossip.

As always, the quality of the student presentations was exceptional. Although prizes were awarded in six categories, many exceptional student presentations went without special recognition. We thank the students and their supervisors for the high quality of their research 
and their presentations. The Martin Aitken Prize for best oral presentation was shared by Johannes Friederich who presented Radiofluorescence as a detection tool for quenching processes in quartz luminescence and Nathan Brown on Using feldspar TL for lowtemperature thermochronology. The Vagn Mejdahl Prize for best poster presentation for applications was shared by Elizabeth Chamberlain (Bleaching differences of modern and late Holocene quartz sediment of the Mississippi River Delta) and Ian del Rio (Potassium feldspar post-IR IRSL dating of uplifted beach-ridges in Mejillones Peninsula, Northern Chile). The John Vogel Prize for the best poster on instrumentation went to Peter Hunter: Thermoluminescence emission from quartz at $480 \mathrm{~nm}$ as a high-dose radiation marker. The Peter Townsend Prize for the most innovative idea in instrumentation and methodology went to Raju Kumar: New insights into the electron trapping centres in feldspar. The prize dedicated to Ann Wintle for the best oral talk on applications went to Harrison Gray: Quantitative connections between luminescence and fluvial sediment transport and Benjamin Lehmann: Combining OSL and Be-10 surface exposure dating to constrain ice-extent histories. The two Nicolas Copernicus Prizes for the brightest young stars went to Aditi Krishna Dave (Archaeological and chronological constraints on the contemporaneity of a Mighty River and the Harappans) and Svenja Riedesel (Constraining the band-tail width of feldspar: implications for luminescence thermochronometry).

The next, 16th International Conference on Luminescence and Electron Spin Resonance Dating will be held in 2020 in Burgos, Spain, and organised by Dr. Gloria Lopez and Dr. Davinia Moreno of the Centro Nacional de Investigación sobre la Evolución Humana (CENIEH). 
As in previous years, the majority of papers presented at the meeting were submitted for publication in either Radiation Measurements or Quaternary Geochronology, the focus of the former being on methodology and the latter on applications. The two volumes of conference proceedings provide a unique insight into the state-of-the-art of the field of luminescence and ESR dating. Check the Science Direct website of Radiation Measurements to catch up with the companion papers. We would like to take this opportunity to thank the large number of colleagues who refereed the submitted papers.

A personal note from Rainer. The LED conference series has been a very important part of my academic life. I have attended the all but the first two meetings in the late 1970s. I have been involved in the editing of the LED conference proceedings since I was first invited as guest editor for the 5th meeting, which was published in 1988. This is the last proceedings volume that I co-edited, as I shall retire at the end of 2019. The LED meetings were always the highlights in my calendar. Rather than scraping the bottom of the barrel, LED researchers saved their cutting edge results for presentations at the LED meetings. I am certain that this tradition will continue for the next 35 years, at least. 